\title{
Acute effects of intrapulmonary percussive ventilation in COPD patients assessed by using conventional outcome parameters and a novel computational fluid dynamics technique
}

This article was published in the following Dove Press journal:

International Journal of COPD

24 September 2012

Number of times this article has been viewed

Kris Ides ${ }^{1-3}$

Wim Vos ${ }^{3,4}$

Lieve De Backer ${ }^{2,3}$

Dirk Vissers ${ }^{1,2}$

Rita Claes ${ }^{2,3}$

Glenn Leemans ${ }^{1,2}$

Kevin Ongena'

Oswald Peters ${ }^{5}$

Wilfried De Backer ${ }^{1-3}$

'Department of Health Science, Artesis University College of Antwerp, Merksem, ${ }^{2}$ Faculty of Medicine and Health Sciences, University of Antwerp, Wilrijk, ${ }^{3}$ Department of Respiratory Medicine, Antwerp University Hospital, Edegem, ${ }^{4}$ FluidDa. nv, Groeningerlei, Kontich, Belgium,

${ }^{5}$ AZ Monica, Antwerp, Belgium
Correspondence: Kris Ides Artesis University College of Antwerp, Department of Health Science, J De Boeckstraat I0, 2170 Merksem, Belgium

Tel +32 382I 3447

Email kris.ides@artesis.be
Objective: Chest physiotherapy enhances sputum evacuation in COPD patients. It can be applied as a single technique or as a combination of techniques including intrapulmonary percussive ventilation (IPV). Recently developed assessment techniques may provide new insights into the effect of airway clearance techniques.

Participants: Five moderate to severe COPD patients (three females and two males; mean forced expiratory volume in 1 second of $39.49 \%$ predicted) who were admitted in the hospital for an acute exacerbation were included in this study.

Methods: A novel imaging technique was used, together with other conventional techniques, to visualize the short-term effects of a single IPV treatment in COPD patients.

Results: No significant changes were noted in the lung function parameters or arterial blood gases measured within 1 hour after the end of the IPV session. Computed tomography images detected changes in the airway patency after the IPV treatment compared with before treatment. Local resistances, calculated for the three-dimensional models, showed local changes in airway resistance.

Conclusion: The effects of a single IPV session can be visualized by functional imaging. This functional imaging allows a calculation of changes in local airway resistance and local changes in airway volume in COPD patients without affecting conventional lung function parameters.

Keywords: IPV, lung function, forced oscillation technique, physical therapy, airway clearance technique

\section{Introduction}

Chest physiotherapy is routinely employed as a prophylactic measure prior to major surgery and postoperatively to prevent respiratory complications such as atelectasis and pneumonia. ${ }^{1}$ At present, only limited evidence is available for some of the physiotherapeutic techniques used in patients with COPD. ${ }^{2,3}$ Physiotherapy treatment enhances sputum evacuation ${ }^{4}$ and can be applied as a single technique but usually a combination of techniques is applied to patients with COPD. Intrapulmonary percussive ventilation (IPV) is a ventilatory technique that uses a device to deliver small bursts of high-flow air into the lungs at high rates, superimposed upon the spontaneous breathing pattern. This causes airway pressures to oscillate between 5 and $35 \mathrm{~cm} \mathrm{H}_{2} \mathrm{O}$ and the airway walls to vibrate in synchrony with these oscillations. A unique sliding venturi, called a phasitron, which is powered by compressed gas at 0.6 to 6 bar, generates these oscillations in the range of 80 to 650 cycles per minute. ${ }^{5}$ 
Although several studies have addressed the physiological effects of IPV when used in COPD patients, there is need for confirmation of its clinical effectiveness. Previously, the effects of IPV in COPD patients were assessed using lung function parameters, arterial blood gases, and duration of hospitalization. Recently developed assessment techniques may give new insights into the effectiveness of airway clearance techniques. One promising new technique is computational fluid dynamics applied to the three-dimensional (3D) images made by CT scanning; this technique allows evaluation of flow and resistance of separate parts of the lung. ${ }^{6,7}$ In the present study, this novel imaging was used, in addition to more conventional outcome parameters, to visualize the effects of a single IPV treatment in COPD patients.

\section{Participants and methods}

Five moderate to severe COPD patients (three females and two males) with Global Initiative for Chronic Obstructive Lung Disease stages 3 to 4, who were hospitalized for an acute exacerbation, were included in this study. Tests were performed before and after IPV treatment in a specific order to minimize the influence on other tests. For pre-treatment tests, the sequence was set as follows: forced oscillation technique (FOT) in upright sitting and supine positions, conventional lung function measurements (including spirometry and body plethysmography measurements), in- and expiratory muscle strength, diffusion capacity, arterial blood gases sampling, and finally a 3D low-dose CT scan was taken within 1 hour prior to the IPV treatment. Patients were asked to score their dyspnea on a Borg dyspnea scale before and after the treatment. After IPV treatment, all tests were repeated in reverse order.

\section{Results and discussion}

Patient results are shown in Table 1. No significant changes were evident in the spirometric or body plethysmographic indices due to IPV treatment. Respiratory muscle strength after a single session tended to decrease, but the changes in inspiratory and expiratory muscle strength were not significantly different. We observed a small but nonsignificant change

Table I Lung function parameters, arterial blood gases, and FOT indices at baseline and after intrapulmonary percussive ventilation treatment

\begin{tabular}{|c|c|c|c|c|c|}
\hline & \multicolumn{2}{|l|}{ Pre } & \multicolumn{2}{|l|}{ Post } & \multirow[t]{2}{*}{$P$ value } \\
\hline & Mean value & SD & Mean value & SD & \\
\hline VC (L) & 2.75 & 0.43 & 2.81 & 0.41 & 0.273 \\
\hline $\mathrm{FEV}_{1}(\% \mathrm{p})$ & 39.49 & 23.62 & 40.27 & 23.23 & 0.225 \\
\hline $\mathrm{FEV}_{1} / \mathrm{VC}(\%)$ & 34.00 & 13.44 & 33.80 & 13.75 & 0.564 \\
\hline TLC (\%p) & 169 & 62 & 168 & 57 & 1 \\
\hline MEF 25 (L/s) & 0.13 & 0.05 & 0.13 & 0.05 & 0.18 \\
\hline MEF 50 (L/s) & 0.34 & 0.23 & 0.35 & 0.27 & 0.785 \\
\hline $\mathrm{RV}(\mathrm{L})$ & 4.86 & 2.19 & 4.61 & 2.34 & 0.686 \\
\hline $\mathrm{DLCO}(\mathrm{mmol} / \mathrm{min} / \mathrm{kPa})$ & 2.99 & 1.49 & 3.25 & 1.76 & 0.138 \\
\hline $\mathrm{DLCO} / \mathrm{VA}(\mathrm{mmol} / \mathrm{min} / \mathrm{kPa} / \mathrm{L})$ & 0.75 & 0.43 & 0.80 & 0.46 & 0.066 \\
\hline $\mathrm{MIP}(\mathrm{kPa})$ & 6.88 & 0.61 & 6.84 & 1.02 & I \\
\hline $\operatorname{MEP}(\mathrm{kPa})$ & 11.54 & 1.14 & 10.22 & 2.72 & 0.068 \\
\hline Borg Dyspnea & 4 & 0.71 & 3.4 & 0.89 & 0.083 \\
\hline $\mathrm{pH}$ & 7.47 & 0.04 & 7.47 & 0.03 & 0.68 \\
\hline $\mathrm{PaO}_{2}(\mathrm{mmHg})$ & 74.88 & 16.10 & 76.52 & 10.30 & 0.893 \\
\hline $\mathrm{PaCO}_{2}(\mathrm{mmHg})$ & 39.32 & 6.50 & 39.60 & 5.98 & 0.343 \\
\hline $\mathrm{HCO}_{3}^{-}(\mathrm{mmol} / \mathrm{L})$ & 27.98 & 4.39 & 28.22 & 4.75 & 0.343 \\
\hline $\mathrm{SaO}_{2}(\%)$ & 95 & 3.00 & 96 & 1.00 & 0.066 \\
\hline Raw (kPa.s/L) & 1.07 & 0.30 & 1.27 & 0.34 & 0.109 \\
\hline sRaw (kPa.s) & 8.30 & 3.39 & 10.22 & 3.86 & 0.109 \\
\hline S_R6 (hPa.s/L) & 4.79 & 0.61 & 5.40 & 0.89 & 0.080 \\
\hline S_R8 (hPa.s/L) & 4.18 & 0.36 & 4.61 & 0.79 & 0.080 \\
\hline L_R6 (hPa.s/L) & 5.88 & 0.85 & 6.27 & 1.35 & 0.465 \\
\hline L_R8 (hPa.s/L) & 5.28 & 0.81 & 5.37 & 0.82 & 0.715 \\
\hline
\end{tabular}

Note: Significance $P<0.05$.

Abbreviations: VC, vital capacity; FOT, forced oscillation technique; \%p, expressed as percentage of the predicted value; FEV , forced expiratory volume in I second; TLC, total lung capacity; MEF 25, maximal expiratory flow when 75\% of FVC is expired; MEF 50, maximal expiratory flow when $50 \%$ of FVC is expired; RV, residual volume; VA, alveolar volume; DLCO, diffusing capacity for carbon monoxide; DLCO/VA, Kroch factor; MIP, maximal inspiratory pressure; MEP, maximal expiratory pressure; Raw, airway resistance; sRaw, specific airway resistance; S_R6, S_R8, Fot resistance at $6 \mathrm{~Hz}$ and $8 \mathrm{~Hz}$, respectively in the sitting position; L_R6, L_R8, Fot resistance at $6 \mathrm{~Hz}$ and $8 \mathrm{~Hz}$, respectively in the supine position. 
iRaw change baseline to post IPV[\%]

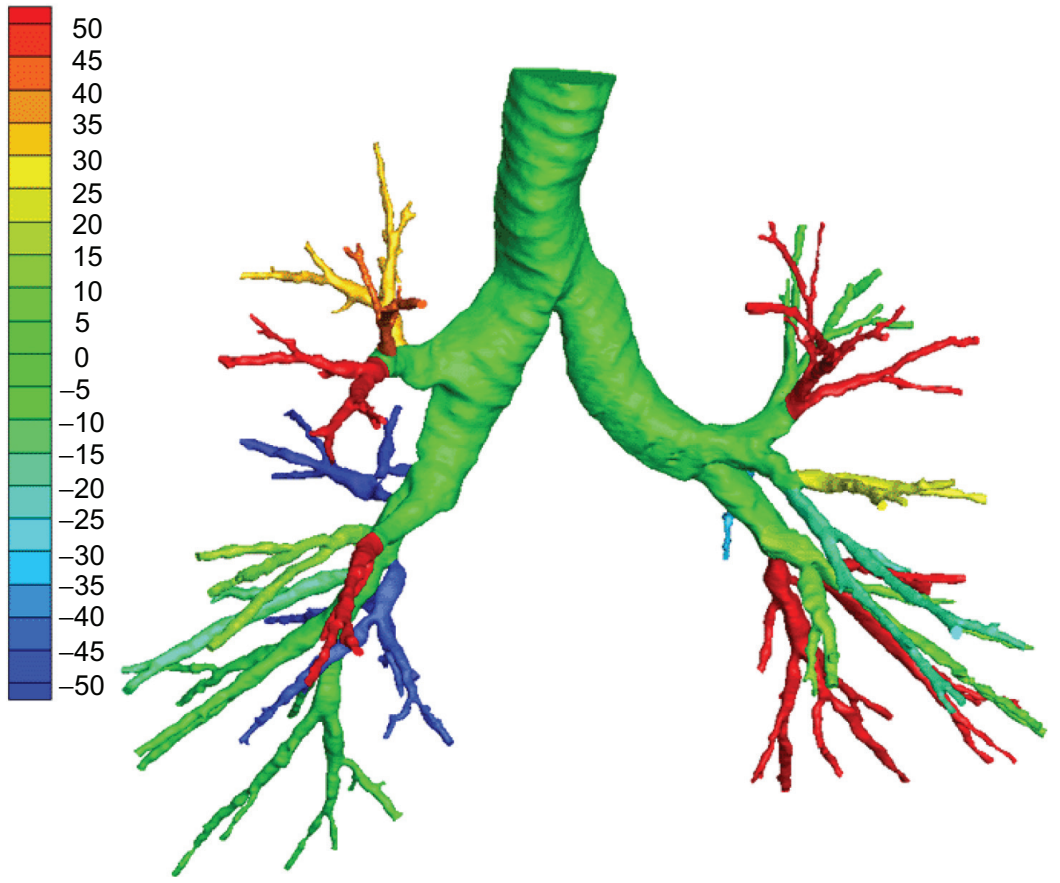

Figure I Changes in airway resistance pre-post intrapulmonary percussive ventilation (IPV) in one representative COPD patient, using a computational fluid dynamic imaging technique.

Abbreviation: iRaw, Relative change in local airway resistance.

in the DLCO/VA (Diffusion capacity of carbon monoxide): corrected for Alveolar volume ratio $(P=0.066)$. Resistance indices, as measured with FOT, did not change significantly.

Four out of five patients coughed up one or more flumes during the IPV treatment. All patients reported that they subjectively felt better after the treatment (the change in Borg dyspnea score, however, was not significant: $P=0.083$ ). Arterial saturation tended to increase after a single IPV session but the changes were not statistically significant $\left(\mathrm{SaO}_{2}\right.$ at baseline and post-IPV treatment: $95 \% \pm 3 \%$ and $96 \% \pm 1 \%$, respectively; $P=0.066$ ).

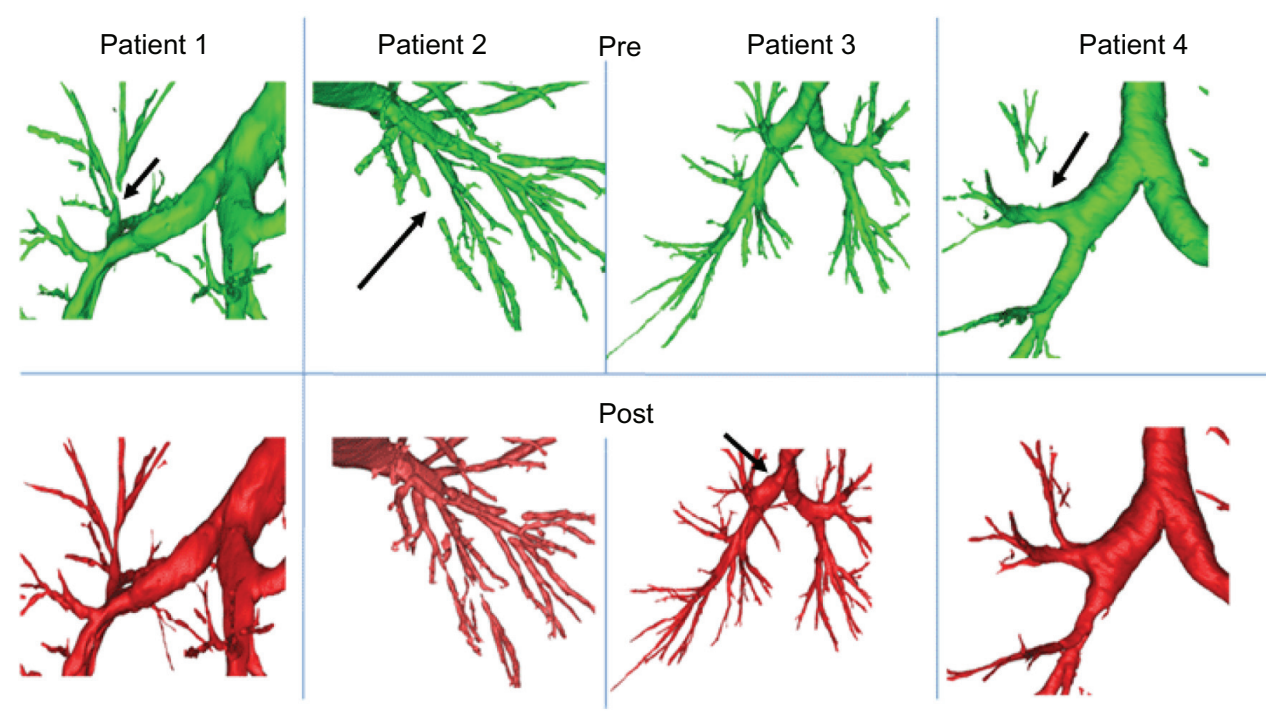

Figure 2 Examples of the comparison of individual airways in different COPD patients as assessed with 3D CT analyses at baseline and after intrapulmonary percussive ventilation (IPV) treatment.

Notes: The upper panels show local airways in different COPD patients as measured at baseline and the bottom panels show the same airways as assessed after IPV treatment. Arrows indicate significant changes in airway patency. 
Table 2 Changes in airway resistance and airway volume induced by a single intrapulmonary percussive ventilation treatment in 5 COPD patients with an acute exacerbation. Changes were calculated using computational fluid dynamics (CFD)

\begin{tabular}{lllllll}
\hline & $\begin{array}{l}\Delta \text { iRaw } \\
\text { total } \\
(\%)\end{array}$ & $\begin{array}{l}\Delta \text { iRaw } \\
\text { central } \\
(\%)\end{array}$ & $\begin{array}{l}\Delta \text { iRaw } \\
\text { distal } \\
(\%)\end{array}$ & $\begin{array}{l}\Delta \text { airway } \\
\text { volume total } \\
(\%)\end{array}$ & $\begin{array}{l}\Delta \text { airway } \\
\text { volume central } \\
(\%)\end{array}$ & $\begin{array}{l}\Delta \text { airway } \\
\text { volume distal } \\
(\%)\end{array}$ \\
\hline PI & 20.03 & -23.72 & 33.13 & 4.05 & 4.23 & 3.38 \\
P2 & -9.61 & 4.80 & -13.14 & 3.80 & 3.86 & 3.62 \\
P3 & -9.83 & 4.29 & -12.24 & 2.15 & 0.85 & 10.85 \\
P4 & 2.65 & -1.21 & 3.69 & -1.66 & -1.77 & -1.41 \\
P5 & 31.65 & 7.35 & 55.36 & -2.91 & -0.22 & -12.25 \\
Mean (SD) & $6.98( \pm 18.41)$ & $-1.70( \pm 12.70)$ & $13.36( \pm 30.03)$ & $1.09( \pm 3.19)$ & $1.39( \pm 2.60)$ & $0.838( \pm 8.53)$ \\
\hline
\end{tabular}

Notes: Central airways are defined as trachea and main bronchea. Distal airways are defined as smaller airways defined for each lobe.

Abbreviations: $\Delta$ iRaw total, changes in airway resistance for the total model; $\Delta$ iRaw central, changes in airway resistance for the central airway model; $\Delta$ iRaw distal, changes in airway resistance for the distal airway model; $\Delta$ airway volume total, changes in airway volume for the total model; $\Delta$ airway volume central, changes in airway volume for the central airway model; $\Delta$ airway volume distal, changes in airway resistance for the distal airway model; PI-P5, patients I to 5 mean values for each parameter; $\mathrm{SD}$, standard deviation.

3D airway reconstructions based on the computed tomography (CT) images were made for each patient. Preintervention images were compared with postintervention images. The images showed differences in the airways after a single IPV session. For example, some peripheral airways that were blocked before the treatment (possibly due to mucus plugging) were reopened after the treatment. Some airway branches were opened up after IPV and other airways were closed after a single IPV session (Figure 2). These changes in airway patency possibly indicate movement or relief of the mucus plugging. The resistance measurements by body plethysmography and FOT both showed a tendency toward an increase in airway resistance. The increase, however, was not statistically significant $(P=0.109$ and $P=0.080$ Alveolar volume for body plethysmography and FOT, respectively).

Computational fluid dynamics (CFD) were used to calculate the local resistances for the different branches in the airways. These resistances did not change significantly. Specific airway resistance, calculated for the local changes in airway resistance, showed changes after the IPV treatment; however, none of the changes were statistically significant. Airway resistance as assessed with body plethysmography and forced oscillations showed similar effects. Although the $3 \mathrm{D}$ computer models showed no changes in the overall airway resistance, local changes were observed, as indicated in Figure 2. Branches with airway blockage in the preintervention scan were reopened in the post scan. In these branches, airway resistance seemed to decrease, possibly due to movement of mucus; however, this is yet to be confirmed by the use of a control group. Table 2 gives an overview of the airway changes observed in the different patients after a single IPV session.
Although data shown here are not compared with the data of a control group, 3D CT imaging has the potential to evaluate the displacement of mucus plugs and removal of mucus plugs in some COPD patients after an IPV treatment. Although we saw changes, the use of a control group is needed to confirm our findings. Our study focused on the visualization of the short-term effects of a single IPV treatment. We used functional imaging to demonstrate that the airway geometry was changed by the IPV session whereas lung function parameters did not show any significant differences. The sample size in the present study is small; more patients are needed to verify these findings.

Patients subjectively reported that they felt better after a single IPV treatment. The accuracy of CT imaging has been confirmed for the assessment of the bronchodilator response in asthmatic patients ${ }^{8}$ and for the particle deposition of an aerosol in the lung. ${ }^{9}$ The usefulness of $3 \mathrm{D}$ imaging and CFD processing has also been shown in the assessment of changes in upper airways ${ }^{10}$ and small airways. ${ }^{11}$ For example, CFD can detect changes in airway resistance in patients with asthma. ${ }^{8}$ One of the main advantages of the CFD method is that this technique allows investigators to make specific models of the patient's airways for use in analyses. ${ }^{12}$ In our study, we demonstrated that the effect of a single IPV treatment could be evaluated using functional imaging. CFD calculations showed a trend towards an increase in total airway resistance.

\section{Conclusion}

Despite its small sample size, this study demonstrated that local treatment effects could be visualized with 3D imaging of the airways. The resulting models allow a calculation of the change in airway volume and change in airway resistance. The technique can be used for comparison with 
traditional outcome parameters, which opens up perspectives for evaluation of physiotherapeutic drainage techniques, and may allow standardization and validation of different airway clearance techniques. Further research should focus on the relationship between mucus displacement and local changes in airway flow and resistance. More studies with larger samples size are needed.

\section{Acknowledgment}

The study has been sponsored by FluidDa.nv.

\section{Disclosure}

The authors report no conflicts of interest in this work.

\section{References}

1. Halpin DM, Miravitlles M. Chronic obstructive pulmonary disease: the disease and its burden to society. Proc Am Thorac Soc. 2006;3: 619-623.

2. Puhan MA, Scharplatz M, Troosters T, et al. Respiratory rehabilitation after acute exacerbation of COPD may reduce risk for readmission and mortality - a systematic review. Respir Res. 2005;6:54.

3. Ides K, Vissers D, De Backer L, et al. Airway clearance in COPD: need for a breath of fresh air? A systematic review. COPD. 2011;8: 196-205.
4. Mikelsons C. The role of physiotherapy in the management of COPD Respir Med: COPD Update. 2008;4:2-7.

5. Vargas F, Bui HN, Boyer A, et al. Intrapulmonary percussive ventilation in acute exacerbations of COPD patients with mild respiratory acidosis: a randomized controlled trial [ISRCTN17802078]. Crit Care. 2005;9: R382-R389.

6. Yen Ha TK, Bui TD, Tran AT, et al. Atelectatic children treated with intrapulmonary percussive ventilation via a face mask: clinical trial and literature overview. Pediatr Int. 2007;49:502-507.

7. Nava S, Barbarito N, Piaggi G, et al. Physiological response to intrapulmonary percussive ventilation in stable COPD patients. Respir Med. 2006;100:1526-1533.

8. De Backer JW, Vos WG, Devolder A, et al. Computational fluid dynamics can detect changes in airway resistance in asthmatics after acute bronchodilation. J Biomech. 2008;41:106-113.

9. De Backer W, Devolder A, Poli G, et al. Lung deposition of BDP/ formoterol HFA pMDI in healthy volunteers, asthmatic, and COPD patients. J Aerosol Med Pulm Drug Deliv. 2010;23:137-148.

10. Vos W DBJ, Devolder A, Vanderveken O, et al. Correlation between severity of sleep apnea and upper airway morphology based on advanced anatomical and functional imaging. J Biomech. 2007;40:2207-2213.

11. De Backer JW, Vos WG, Gorle CD, et al. Flow analyses in the lower airways: patient-specific model and boundary conditions. Med Eng Phys. 2008;30:872-879.

12. De Backer JW, Vos WG, Vinchurkar SC, et al. Validation of computational fluid dynamics in CT-based airway models with SPECT/CT Radiology. 2010;257:854-862.
International Journal of COPD

\section{Publish your work in this journal}

The International Journal of COPD is an international, peer-reviewed journal of therapeutics and pharmacology focusing on concise rapid reporting of clinical studies and reviews in COPD. Special focus is given to the pathophysiological processes underlying the disease, intervention programs, patient focused education, and self management protocols.

\section{Dovepress}

This journal is indexed on PubMed Central, MedLine and CAS. The manuscript management system is completely online and includes a very quick and fair peer-review system, which is all easy to use. Visit http://www.dovepress.com/testimonials.php to read real quotes from published authors. 